\title{
Study on antibacterial activity and self-assembly of ovalbumin- derived peptides
}

\author{
Ao Tan ${ }^{1, a}$, Hiroyuki Konno ${ }^{2, b^{*}}$ \\ ${ }^{1}$ Graduate School of Science and Engineering, Yamagata University, Yonezawa, Yamagata 992-8510, Japan \\ ${ }^{2}$ Graduate School of Science and Engineering, Yamagata University, Yonezawa, Yamagata 992-8510, Japan
}

\begin{abstract}
Antimicrobial activity and self-assembly of the modified TK913 peptide are described. We designed the peptides TK9Z1-4 and TKZ2-3 based on the TK913 sequence and prepared these peptides by Fmoc-SPPS. TKZ3 shows morphology change in the different concentration and potent antimicrobial activities. In addition, TKZ3 has stability in trypsin treatment.
\end{abstract}

\section{Introduction}

Antimicrobial peptides (AMPs) are produced by most living entities (microorganisms, animals and plants) to defend against invading organisms. Due to its unique antibacterial method, it is difficult for bacteria to recognize AMPs.(1) Although more than 5,000 AMPs have been discovered in the past five decades, $(2,3)$ only nine cyclic AMPs have been found for medical use. Most of linear peptides are unstable in the digestive system and therefore it is difficult to use in animal husbandry and industries. In contrast, linear peptides are easily prepared by solid phase techniques and quickly evaluated against antimicrobial activities.

The goal of our research is the focus on the improvement of stability of AMPs by forming the rigid secondary structures. In the present research, we report the preparation of the peptide TK913(4) with the negatively charged amino acids on the hydrophilic surface to form high-ordered structure by self-assembly and evaluation of antimicrobial activities.

\section{Results and Discussion}

The presence of positively charged amino acids on the hydrophilic surface of cationic helical AMPs performs anti-bacterial activity, and the hydrophobic surface of these peptides provides the ability to insert into cell membranes through lipo-soluble hydrophobic amino acids. These AMPs tend to self-assemble into a hydrophobic environment due to hydrophobic interactions, forming small-sized aggregates with the hydrophobic inside face and the hydrophilic outside face. Our aim is to block positively charged amino acids through self-assembly and enhance stability without decreasing the antimicrobial activity produced by the peptide sequences.(5) Therefore, the sequence of the AMPs can't be modified to prevent affect the amphipathicity. The TK913 peptide produced by our group were connected with amino acids with hydrophobic folding tendency at the C-terminal or $\mathrm{N}$ terminal with $\beta$-turn like motif. $(6,7)$ It means to retain the ability to insert into the cell membrane. For the reason, we planned to bind the negatively charged amino acids at (i, $\mathrm{i}+7)$ and $(\mathrm{i}, \mathrm{i}+2)$ positions; $(8,9,10)$ corresponding to positively charged amino acids to synthesize the peptide TK913 analogues. It is expected that through hydrophobic and electrostatic interaction. The peptides TK9Z1-4 were prepared by Fmoc-SPPS and measured by SEM and CD spectra. In addition, anti-bacterial activity of TK9Z1-4 was evaluated using several bacteria.

Table 1. Anti-bacterial activity of TK9Z1-4.

\begin{tabular}{|c|c|c|c|c|c|c|}
\hline compounds & Peptide sequence & M.luteus & S.epidermidis & S.cerevisiae & C.viswanathii & $\begin{array}{c}\text { A.oryz } \\
\text { aes }\end{array}$ \\
\hline TK9Z1 & RKIKRYLRRMIIMQQLYQEIEQ & $>800$ & $>800$ & $>800$ & $>800$ & $>800$ \\
\hline TK9Z2 & RKIKRYLRRMIPPIMQQLYQEIEQ & 400 & 400 & 800 & 800 & 800 \\
\hline
\end{tabular}

atck53159@st.yamagata-u.ac.jp

* Corresponding author: ${ }^{\text {b*k} k o n n o @ y z . y a m a g a t a-u . a c . j p ~}$ 


$\begin{array}{ccccccc}\text { TK9Z3 } & \text { RKIKRYLRRMIIMEQLYQQIEQ } & >800 & >800 & >800 & >800 & >800 \\ \text { TK9Z4 } & \text { RKIKRYLRRMIPPIMEQLYQQIEQ } & 200 & 400 & 800 & 800 & 800\end{array}$

Though anti-microbial activities of the peptides TK9Z1-4 have been hardly showed against five microbials as shown in Table 1, the nanostructures of the peptides TK9Z1-4 were investigated by SEM (data not shown). The SEM images exhibited the nanostructure of TK9Z4 by the self-assembly that formed long twisting nanofibrils with a diameter of $50 \mathrm{~nm}$. The morphology changes of the peptides TK9Z2 and TK9Z4 at different concentrations was investigated by the measurement of $\mathrm{CD}$ spectra. When it is lower than $12.5 \mu \mathrm{m}$, it is a $\beta$-sheet structure. It is a $\alpha$-helix structure as higher than $12.5 \mu \mathrm{m}$. When it is higher than $50 \mu \mathrm{m}$, it is a random coil (Fig. 1b). It can be known from SEM image and CD spectra that Pro-Pro motif is connected to TK9Z2 as a hydrophobic core and negatively charged amino acids are added to the $(i, i+2)$ positions, which can only form irregular spherical aggregates with $\beta$-sheet formation (Fig. 1a). It suggests that the secondary structure of TK9Z4 has changed at different concentrations and carried out the nanostructures by the self-assembly.
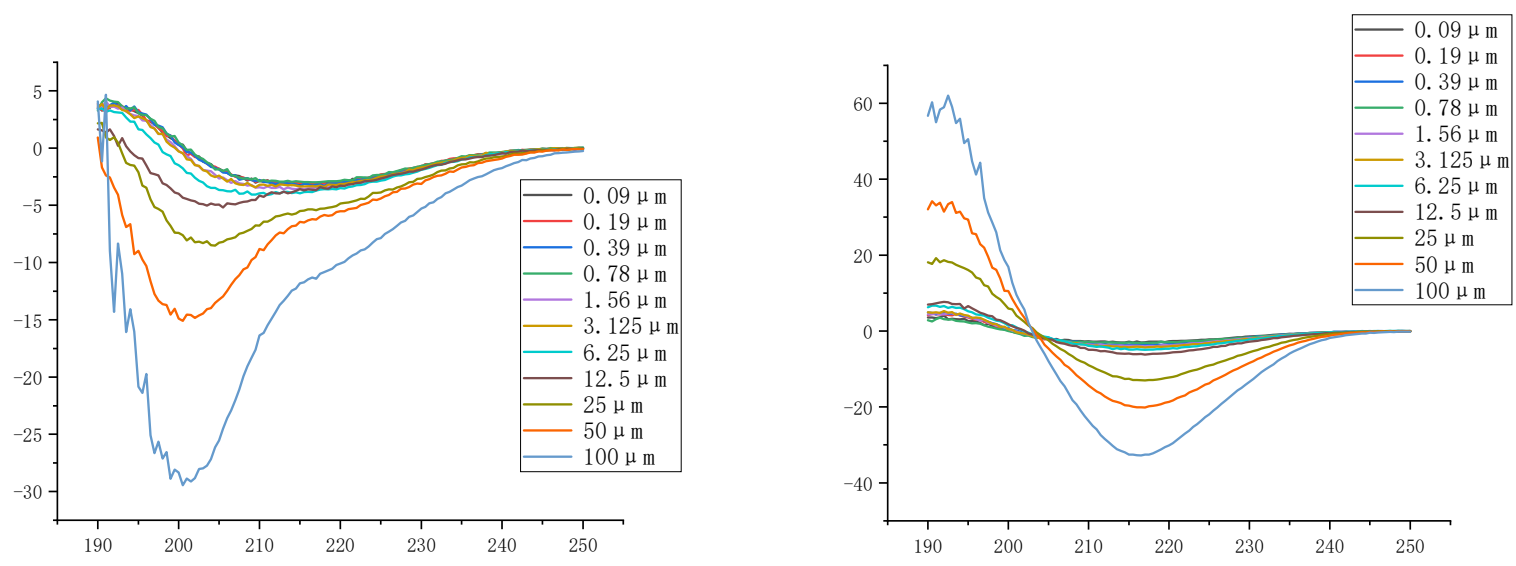

Fig. 1. CD spectra of the peptides at different concentrations (a) TK9Z2 and (b) TK9Z4.

We designed TKZ3 peptide with the salt bridge between three Glu residues and Arg or Lys residues on (i, $\mathrm{i}+2, \mathrm{i}+7)$ positions. CD spectra of TKZ3 showed similar with those of TK9Z4. Anti-microbial activity of YKZ2 and TKZ4 were evaluated against microbials as shown in Table 2. Surprisingly, the peptide TKZ3 showed potent anti-microbial activities with the MIC values of 12.5-100 $\mathrm{mg} / \mathrm{ml}$. Although these results were slightly weak compared with those of the peptide TK913, it was enough to be candidate peptide for the AMP of next generation (Table 2).

Table 2. Antimicrobial activities of all peptides.

\begin{tabular}{|c|c|c|c|c|c|c|}
\hline compounds & Peptide sequence & M.luteus & S.epidermidis & E.coli & S.cerevisiae & A.oryzaes \\
\hline TK913 & RKIKRYLRRMI & 3.125 & 25 & 6.25 & 12.5 & 12.5 \\
\hline TKZ2 & RKIKRYLRRMIPPIMRRLYRKIKR & 100 & 50 & 800 & 200 & 800 \\
\hline TKZ3 & RKIKRYLRRMIPPIMRELYREIER & 12.5 & 25 & 100 & 25 & 50 \\
\hline
\end{tabular}


Next, we investigated the stability of TK9Z2, TK9Z4 and TKZ3 by the digestion condition. TKZ2 was used as a control peptide. Four peptides with trypsin were treated in PBS buffer for one week. This reaction was monitored by HPLC as shown in Fig. 2. After the treatment of $5 \mathrm{~h}$,
55\% TK9Z2 and 32\% TK9Z4 remained and TKZ2 was almost digested in this condition. On the other hand, TKZ3 resisted against trypsin and survived about $87 \%$. After 7 days, the peak of TKZ3 was detected with $52 \%$ on HPLC (Fig. 2).

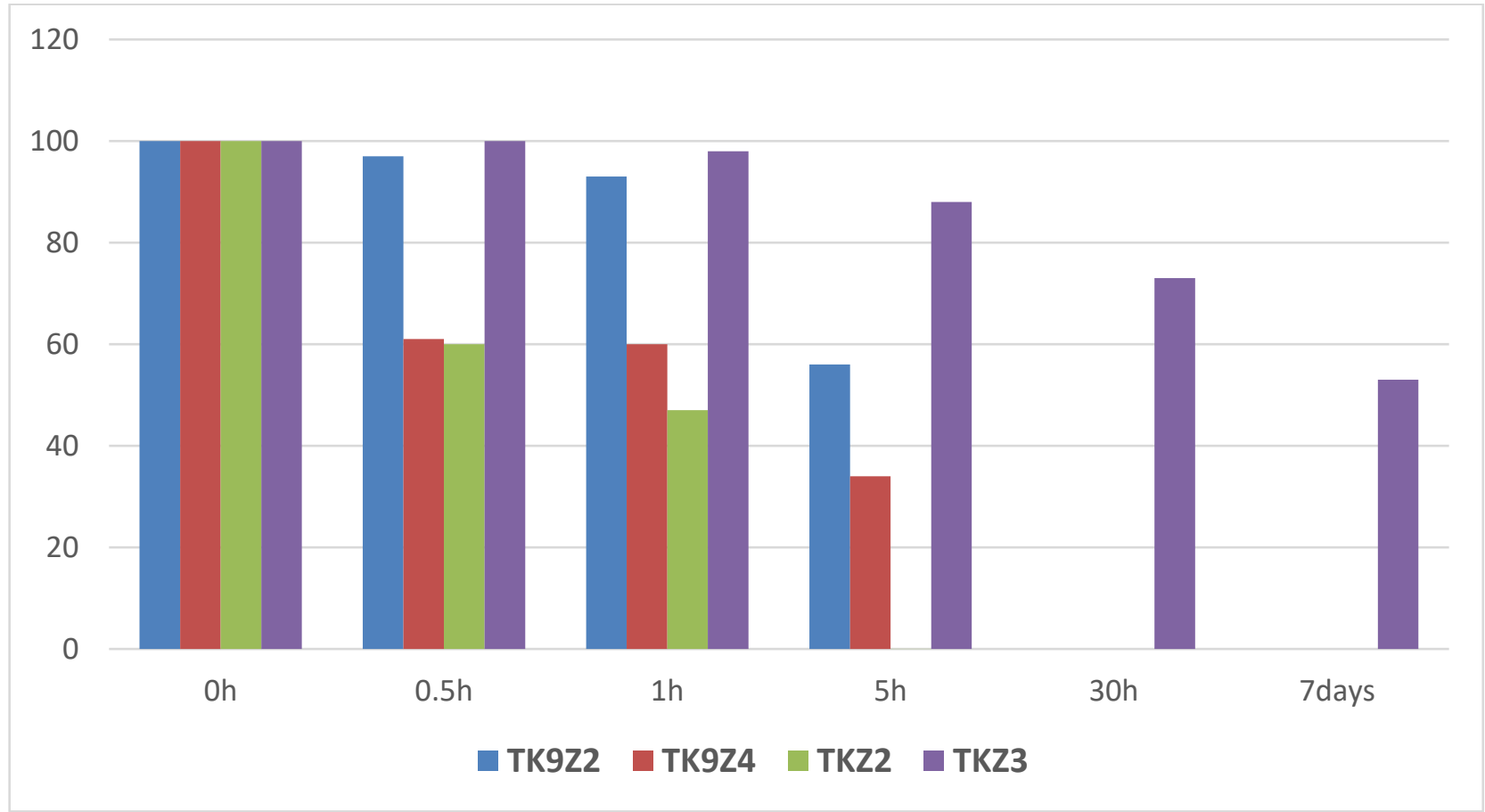

Fig. 2. Proteolytic digestion of the peptides TK9Z3-4, TKZ1 and TKZ3.

\section{Conclusion}

Antimicrobial peptides (AMPs) are produced by most living entities (microorganisms, animals and plants) to defend against invading organisms. Due to its unique antibacterial method, it is difficult for bacteria to recognize AMPs.(1) Although more than 5,000 AMPs have been discovered in the past five decades, $(2,3)$ only nine cyclic AMP The peptide TK913analogues bound the additional sequence were synthesized by Fmoc-SPPS. The peptide TK9Z4 with the negative charged amino acid residue Glu at $(i, i+7)$ positions formed to nanowires by self-assembly. The peptide TK3Z with the negatively charged amino acid residue Glu at $(i, i+2, i+7)$ positions formed to nanostructures and has stability in trypsin treatment for 1 week. In addition, TKZ3 still has potent antimicrobial activity.

\section{Acknowledgement}

This research was supported by the Yamagata University YU-COE(C) program and Yonezawa Engineering Society.

\section{References}

1. Sayed S, Jardine M A. Antimicrobial biopolymers. Advanced Functional Materials; John Wiley \& Sons, Inc.: Hoboken, NJ, USA, 2015: 493-533.

2. Actis M L, Ambaye N D, Evison B J, Shao Y,
Vanaritti M, Inoue A, McDonald E T, Kikuchi S, Heath R, Hara K, Hashimoto H, Fujii N. Identification of the first small-molecule inhibitor of the REV7 DNA repair protein interaction. Bioorg Med Chem 2016, 24: 4339-4346.

3. De la Torre B G, Albericio F. Pep Therapeutics 2.0. 2020.

4. Tan A, Suzuki R, Yokoyama C, Yano S, Konno H. Antimicrobial activity and secondary structure of a novel peptide derived from ovalbumin. J Pep Sci 2020, 26:e3276.

5. Heissel S, Frederiksen S J, Bunkenborg J, Hojrup P. Enhanced trypsin on a budget: Stabilization, purification and high-temperature application of inexpensive commercial trypsin for proteomics application. Plos One 2019, 14: e0218374.

6. Sun J, Xia Y, Li D, Du Q, Liang, D. Relationship between peptide structure and antimicrobial activity as studied by de novo designed peptides. Biochim Biophys Acta-Biomembranes 2014, 1838: 2985-2993.

7. Juhaniewicz J, Szyk-Warszyńska L, Warszyński P, Sek S. Interaction of cecropin B with zwitterionic and negatively charged lipid bilayers immobilized at gold electrode surface. Electrochimica Acta 2016, 204 : 206-217.

8. Pace C N, Scholtz J M. A helix propensity scale based on experimental studies of peptides and proteins. Biophys J 1998, 75: 422-427.

9. Müller G, Gurrath M, Kurz M, Kessler H. $\beta$ VI turns 
in peptides and proteins: A model peptide mimicry. Proteins: Structure, Function, and Bioinformatics 1993, 15: 235-251.

10. Lau Y H, De Andrade P, Wu Y, Spring D R. Peptide stapling techniques based on different macrocyclization chemistries. Chem Soc Rev 2015, 44: 91-102.

11. Cromm P M, Spiegel J, Grossmann T N. Hydrocarbon stapled peptides as modulators of biological function. ACS Chem Biol 2015, 10: 1362-1375. 